\title{
A COUPLED RELAP5-3D/CFD METHODOLOGY WITH A PROOF-OF-PRINCIPLE CALCULATION
}

\author{
D. L. AUMILLER
}

E. T. TOMLINSON

R. C. BAUER

DE-AC11-98PN38206

\section{NOTICE}

This report was prepared as an account of work sponsored by the United States Government. Neither the United States, nor the United States Department of Energy, nor any of their employees, nor any of their contractors, subcontractors, or their employees, makes any warranty, express or implied, or assumes any legal liability or responsibility for the accuracy, completeness or usefulness of any information, apparatus, product or process disclosed, or represents that its use would not infringe privately owned rights.

Operated for the U.S. Department of Energy

by Bechtel Bettis, Inc. 


\section{DISCLAIMER}

This report was prepared as an account of work sponsored by an agency of the United States Government. Neither the United States Government nor any agency thereof, nor any of their employees, make any warranty, express or implied, or assumes any legal liability or responsibility for the accuracy, completeness, or usefulness of any information, apparatus, product, or process disclosed, or represents that its use would not infringe privately owned rights. Reference herein to any specific commercial product, process, or service by trade name, trademark, manufacturer, or otherwise does not necessarily constitute or imply its endorsement, recommendation, or favoring by the United States Government or any agency thereof. The views and opinions of authors expressed herein do not necessarily state or reflect those of the United States Government or any agency thereof. 


\section{DISCLAIMER}

Portions of this document may be illegible in electronic image products. Images are produced from the best available original document. 


\title{
A COUPLED RELAP5-3D/CFD METHODOLOGY WITH A PROOF-OF-PRINCIPLE CALCULATION
}

\author{
D.L. Aumiller \\ E.T. Tomlinson \\ R.C. Bauer \\ Bechtel Bettis, Inc. \\ Bettis Atomic Laboratory \\ P.O. Box 79 \\ West Mifflin, PA 15122-0079
}

\begin{abstract}
$\underline{\text { Abstract }}$
The RELAP5-3D computer code was modified to make the explicit coupling capability in the code fully functional. As a test of the modified code, a coupled RELAP5/RELAP5 analysis of the Edwards-O'Brien blowdown problem was performed which showed no significant deviations from the standard RELAP5-3D predictions. In addition, a multiphase Computational Fluid Dynamics (CFD) code was modified to permit explicit coupling to RELAP5-3D. Several calculations were performed with this code. The first analysis used the experimental pressure history from a point just upstream of the break as a boundary condition. This analysis showed that a multiphase CFD code could calculate the thermodynamic and hydrodynamic conditions during a rapid blowdown transient. Finally, a coupled RELAP5/CFD analysis was performed. The results are presented in this paper.
\end{abstract}

\section{Introduction}

One of the interesting problems in safety analysis has always been how to provide the desired degree of physical modeling without burdening the user with unreasonable run times. One solution to this problem has been to couple a detailed, three-dimensional code to a safety code. The best known example of this is the COBRA/TRAC code.[1] More recently, RELAP5/MOD3 has been linked to additional codes to provide a more complete analysis of LOCA phenomena. Examples of this are the coupling of the RELAP5/MOD3 and CONTAIN codes [2] and the coupling of the RELAP5/MOD3 and COBRA-TF codes. $[3,4]$

Computational Fluid Dynamics (CFD) codes are capable of calculating much more detailed flow field predictions through the use of more detailed physical models, however, they have not been utilized for safety analyses. The primary reasons for this have been the general lack of multiphase CFD codes and the exorbitant run time usually associated with these codes. Recent work in the area of multiphase CFD and the advent of ever faster computers have made it feasible to perform some CFD based calculations in the context of a safety analysis.
This paper describes scoping work which was performed to couple a multiphase CFD code to RELAP5-3D and presents the results of a proof-ofprinciple analysis which was performed using this coupled version of RELAP5-3D.

\section{Description of the CFD Code}

With recent advances in the multi-phase CFD codes, any of a number of commercially available codes could have been used as the test platform for this work. The CFD code which was chosen to be coupled with RELAP5-3D was based from the CFDS-FLOW3D [5] (now CFX) code. The code has been modified to provide multidimensional, multifield, heated, two-phase flow capability. A four-field formulation [continuous liquid, dispersed vapor (bubbles), continuous vapor and dispersed liquid (drops)] is used to represent the complete range of two-phase flow patterns from bubbly through annular flow more accurately.

In the three-dimensional, four-field formulation, a total of 25 coupled conservation equations are solved at each mesh point. The four fields are characterized by 12 velocity components, four volume fractions, one common pressure, four temperatures, two turbulence kinetic energies and two turbulent energy dissipation 
rates for the continuous phases and four characteristic lengths (e.g., bubble or droplet diameter or liquid film thickness). The fields are coupled through interfacial heat and mass transfer, interfacial forces, interfield mass transfer and interfacial area. Although the code is capable of four field analysis, the work described herein is restricted to two fields.

A number of spatial differencing schemes are available in the CFD code. To maintain consistency with the RELAP5-3D code, the first order accurate donor cell differencing scheme was selected. Fully-implicit time differencing was also used in this analysis.

\section{Generic Coupling Issues}

When coupling any dissimilar codes, there are a number of generic issues which must be addressed to assure that mass, momentum and energy are conserved. Among the generic issues which will be discussed in this section are:

- the frequency and point in the solution procedure where the data are transferred between the codes

- which code will calculate which terms in the solution scheme

- the definition of the variables which will be passed between the codes

- the method of time step control

The work described in this paper makes use of an explicit coupling technique. It was deemed prudent to perform an explicitly coupled proof-of-principle calculation before a more difficult semi-implicit coupling was attempted. Since the coupling is explicit, all of the pertinent information can be exchanged at the beginning of the hydraulic solution for each timestep.

Figure 1 is an illustration of the calculational domains used in the coupled analysis. The figure shows the location and direction of the data which are transmitted between codes and, for comparison, provides a schematic of the full RELAP5-3D model of the same problem.

As can be seen in Figure 1, the coupling is performed by using artificial boundary conditions in each of the codes. The RELAP5-3D portion has a time dependent volume (TDV) and a time dependent junction (TDJ). The conditions in the TDV are only used for determining the donored quantities and are provided by the appropriate node in the CFD portion. The phasic mass flow rates for the TDJ are calculated in the CFD portion of the code. Table 1 identifies the variables that are transmitted
Table 1: List of Transmitted Data

\begin{tabular}{|c|c|}
\hline RELAP5-3D $\rightarrow$ CFD & CFD $\rightarrow$ RELAP5-3D \\
\hline $\begin{array}{c}\text { pressure } \\
(\mathrm{p})\end{array}$ & $\begin{array}{c}\text { pressure } \\
(\mathrm{p})\end{array}$ \\
\hline $\begin{array}{c}\text { liquid density } \\
\text { (rhof) }\end{array}$ & $\begin{array}{c}\text { liquid internal energy } \\
\text { (uf) }\end{array}$ \\
\hline $\begin{array}{c}\text { gas density } \\
\text { (rhog) }\end{array}$ & $\begin{array}{c}\text { gas internal energy } \\
\text { (ug) }\end{array}$ \\
\hline $\begin{array}{c}\text { liquid temperature } \\
\text { (tempf) }\end{array}$ & $\begin{array}{c}\text { void fraction } \\
\text { (voidg) }\end{array}$ \\
\hline $\begin{array}{c}\text { gas temperature } \\
\text { (tempf) }\end{array}$ & $\begin{array}{c}\text { liquid mass flow rate } \\
\text { (mflowjf) }\end{array}$ \\
\hline $\begin{array}{c}\text { void fraction } \\
\text { (voidg) }\end{array}$ & $\begin{array}{c}\text { gas mass flow rate } \\
\text { (mflowjg) }\end{array}$ \\
\hline
\end{tabular}

There are several points that need to be discussed based on the table. Most of them are directly related to the use of different independent variables in the codes and to the use of different water properties in the two codes. The first is the need to convert the energy variables between the two codes. Specific internal energy (u) is the independent variable used in RELAP5-3D, whereas, the CFD code uses an enthalpy (h) based formulation. Therefore, a change in variables is required at the interface. In this implementation, the codes were configured to have the code sending the data convert the information before being sent. An equally valid implementation, would be to have the receiving code translate the data from the variable used in the sending code to its energy variable.

Another issue concerning the specification of variables is the fact that temperature and not enthalpy is sent to the CFD code. This decision was influenced by the use of separate water property packages in the RELAP5-3D and the CFD code. It was deemed more important to have consistent temperatures in the CFD code, so that the interfacial heat transfer would be correct, than having consistent enthalpies in the codes. In future implementations of this coupling, consistent water properties will be used and this issue will become moot.

Also because of the different water properties, the phasic densities are passed to the CFD code to provide the correct value for donoring the convection terms.

The final issue which must be dealt with is ensuring that codes advance in a uniform manner (i.e. both think the transient time and timestep size are the same). This issue was solved using the simple procedure of running both codes with a fixed timestep size. Using this technique, if the CFD code could not converge at the specified 
timestep size, the run was aborted. Work is currently being performed to provide a more elegant and robust solution to this problem.

For this implementation, mass and energy are conserved, however, momentum is not conserved. This is because both RELAP5-3D and the CFD code do not have all of the required information to correctly calculate the $\mathrm{V} \nabla \mathrm{V}$ term at the pressure boundary locations. Since this term is not correctly calculated, momentum is not conserved in this scoping study. This error will be most significant where there is a significant velocity gradient in the problem. The error associated with the non-conservation of momentum is deemed to be small for this problem. This is based on the fact that as will be shown later, the RELAP5/RELAP5 coupled results are almost identical to the standard RELAP5-3D predictions. As part of ongoing work in enhancing the coupling of RELAP5-3D to other codes, methods for conserving momentum are being developed and implemented.

\section{RELAP5-3D Coupling Issues}

Two modifications were needed to the RELAP5-3D program to provide an explicit coupling capability with other codes. The Parallel Virtual Machine (PVM) [6] protocol was used as the method for transferring data. The original coupling work using PVM was performed by Martin [7], but never fully implemented in the released versions of RELAP5-3D. In the partial implementation of this work in RELAP5-3D, each datum was passed a separated message. This implementation was completed and tested using a RELAP5/RELAP5 coupled problem. The time required to run the Edward's-O'Brien blowdown problem increased by a factor of 5 which was unacceptable for real applications work.

The implementation was modified to permit the analyst to assign a number of data items to a single message (e.g., one for the send message and one for the receive message). This reduced the number of messages that needed to be sent at each time step and reduced the overhead for running the coupled problem from a factor of 5 to a factor of 1.3. The authors believe that this probably represents an upper bound on the runtime penalty as the "grind" time for the Edward's-O'Brien blowdown problem is insignificant and the inter time step processing dominates the calculation even in the uncoupled problem.
The second modification to the RELAP5-3D code was to add the capability to specify the phasic mass flow rate in time dependent junctions. The programing for both of these modifications have been provided to INEEL for inclusion in the released version of RELAP5-3D.

\section{CFD Coupling Issues}

Although the CFD code is capable of performing threedimensional, four-field calculations of two-phase flow, the analysis which is presented here is one-dimensional, two-field, and does not use a turbulence model. This simplification was performed via input on the CFD code. Since the additional work required to add in the full three-dimensional and four-field capability was deemed to be substantial, this intermediate, proof-ofprinciple test was performed.

The implementation of the coupling in the CFD portion of the code made use of the CFX USRBCS subroutine. This subroutine was provided by the vendor to allow the user to change the boundary condition data. Although, this approach worked well for this problem, a dedicated coupling package is currently under development to allow more sophisticated coupling to the full multidimensional, four-field CFD capability.

\section{Description of Test}

The Edwards-O'Brien experiments consisted of fluid depressurization studies in a straight pipe $4.096 \mathrm{~m}$ (13.44 ft.) long with an inside diameter of $0.073 \mathrm{~m}$ (2.88 in.). The pipe was filled with water and brought to initial conditions ranging from $3.55 \mathrm{MPa}$ (500 psig) and $514.8^{\circ} \mathrm{K}\left(467^{\circ} \mathrm{F}\right)$ to $17.34 \mathrm{MPa}(2500 \mathrm{psig})$ and $616.5^{\circ} \mathrm{K}\left(650^{\circ} \mathrm{F}\right)$. Standard Problem 1 was performed at nominal initial conditions of $7.00 \mathrm{MPa}(1000 \mathrm{psig})$ and $513.7^{\circ} \mathrm{K}\left(465^{\circ} \mathrm{F}\right)$.

A glass disk at one end of the pipe was designed to rupture with a single shot from a pellet gun to initiate the depressurization phase of the transient. The time for the disk to fully open was estimated to be $1.0 \mathrm{~ms}$. Following the experiment, a small amount of glass was observed around the circumference of the opening. Based on this observation, the break flow area was reduced by $13 \%$ from the pipe cross sectional area.

Fast response temperature and pressure measuring instruments were located along the length of the pipe. The detector locations (gauge stations) were identified as GS-1 through GS-7 and positioned as shown in Figure 2. 
Data obtained from the experiment included time dependent pressures at each of the gauge stations and temperature and void fraction information at GS-5. These parameters were measured for $600 \mathrm{~ms}$. after the initiation of the depressurization.

\section{RELAP5/RELAP5 Test Case}

The RELAP5-3D standard installation problem (edhtrh.i) was modified for use in this calculation. The nodalization for the uncoupled and the RELAP5/RELAP5 coupled problem are presented in Figure 1. The use of explicit coupling dictates that a time step on the order of the inverse of the sonic velocity be used to capture the effects of the propagation of the pressure wave up the pipe. Both the uncoupled and the coupled problems were run using the semi-implicit time integration scheme at a time step of 0.1 milliseconds. This timestep size is much larger than the sonic velocity based Courant number, therefore, numerical instabilities related to the explicit coupling were expected before the calculation was performed.

Comparisons of the coupled RELAP5/RELAP5 and standalone RELAP5-3D predicted pressure and void fraction at GS-5 are presented in Figures 3 and 4, respectively. These results show that the coupled results closely match the full model results. The same pressure and void fraction comparisons for GS-7, located near the closed end of the pipe, are presented in Figures 5 and 6 , respectively. These plots also show good agreement between the coupled RELAP5/RELAP5 and standalone RELAP5-3D analyses.

Figure 7 presents the mass flow rate at coupling junction and the corresponding location in the full RELAP5-3D model. This figure shows a noticeably larger mass flow overshoot in the RELAP5/RELAP5 coupled case as the void fraction begins changing at this junction $(\sim 0.125-$ $0.130 \mathrm{sec}$.). Otherwise, agreement between the calculations is good. The authors believe that the larger overshoot is an artifice of the explicit coupling used in this calculation and the non-conservation of momentum. Work is currently underway to develop a semi-implicit coupling technique for RELAP5-3D. The semi-implicit coupling will remove the numerical instabilities associated with current explicit coupling when timesteps larger than the sonic velocity based Courant limit are utilized. Therefore, timestep sizes consistent with the normal RELAP5-3D restrictions (i.e. the material Courant limit) will be allowed without the coupling causing any numerical instabilities.

\section{Standalone CFD Results}

To determine if the CFD code could calculate the conditions in the blowdown experiment, a standalone CFD analysis was performed. An input deck similar to one described in the previous section was created for the CFD code. This deck is one-dimensional and did not use the turbulence models. Again, it needs to be stated that this and the coupled analysis are viewed as proof-ofprinciple exercises and not assessment quality work.

There is one important difference between the RELAP5-3D model and the CFD model; i.e. how the exit boundary condition was handled. In the RELAP53D model, the break flow area and the downstream pressure were explicitly modeled. The RELAP5-3D critical flow model was then used to determine the exiting mass flow rate. However, the CFD code has no two-phase critical flow model, therefore an alternate modeling was used. In this analysis, the experimental pressure history from GS-1, the closest to the break, was used as the boundary condition.

The results of the pressure and void fraction predictions for GS-5 and GS-7 are shown in Figures 3 through 6. Several interesting trends are exhibited in these figures. The first is that all of the predictions are smoother for the standalone CFD case than for RELAP5-3D. The use of fully implicit numerics may be responsible for this behavior.

The results of the standalone CFD analysis indicated that the CFD code was capable of calculating the rapidly changing conditions in this problem. Based on these results it was decided to perform the coupled RELAP5/CFD analysis.

\section{RELAP5/CFD Coupled Analysis}

A coupled RELAP5/CFD calculation was performed using the nodalization shown in Figure 1. The results of the this calculation for the pressure and void fraction at GS-5 and GS-7 are coplotted with the previously described analyses and are shown in Figures 3 through 6. Both GS-5 and GS-7 are located in the CFD part of the problem.

It is interesting to note that the predictions for the coupled analysis are not bounded by the standalone RELAP5-3D and standalone CFD calculations. This can be traced back to the interaction of the two different parts of the coupled solution. From Figure 4, it can be seen that during the early part of the transient $(0.0$ $0.1 \mathrm{sec}$.), the CFD code predicts a lower void fraction 
than the RELAP5-3D calculations. Additionally, Figure 7 shows that the mass flow rate at the coupling location is considerably larger for the coupled RELAP5/CFD calculation than for standalone RELAP5-3D analyses. This combination of lower void fraction and higher mass flow rates are related in that a lower void fraction implies a larger mass flow rate because of its associated larger two-phase density.

This relationship is more important at the break location where the flow is limited by the critical flow rate which is strongly void fraction dependent. The void fraction and break flow predictions for the different calculations are shown in Figures 8 and 9, respectively. From Figure 8 it can be seen that the void fraction at the break is predicted to be smaller in coupled RELAP5/CFD calculations than in the other RELAP5-3D predictions. This plot also shows that the CFD code flashes at a much slower rate than RELAP5-3D (as also seen in Figure 4). This lower void fraction yields a significantly higher break flow as seen in Figure 9. The removal of a larger amount of mass requires the coupled RELAP5/CFD case to void much more quickly at locations upstream of the break in order to conserve mass.

To summarize, the CFD portion flashes at a slower rate than RELAP5-3D resulting in more fluid being removed from the pipe in the initial part of the transient. This larger mass flow rate reduces the liquid inventory in the CFD portion of the problem, which causes rapid flashing in order to conserve mass. Therefore, the reluctance of the CFD portion to flash, based on the thermal non-equilibrium, indirectly causes a more rapid voiding in the CFD part of the code due to mass transfer effects.

\section{Conclusions}

The work presented in this paper shows that it is possible to couple a CFD code to a safety code. The concept of coupling codes allows the advanced physics of the CFD code to be discriminately applied to those areas of the problem where knowledge of the detailed flow field supports determination of key safety analysis parameters.

Additionally, a proof-of-principle calculation was performed using the Edwards-O'Brien experiment. This analysis showed that the multiphase CFD codes have matured to the point where they are capable of calculating the conditions in a rapidly changing, twophase environment.
The addition of the detailed physics associated with the multiphase CFD codes to RELAP5-3D has the potential to greatly enhance the accuracy of safety calculations in areas where such accuracy is needed.

\section{References}

[1] Koontz, A.S. and J.M. Cuta, "COBRA/TRAC - A Thermal-Hydraulics Code for Transient Analysis of Nuclear Reactor Vessels and Primary Coolant Systems" NUREG/CR-3046, 1983.

[2] Smith, K.A., et al., "Coupled RELAP5 and CONTAIN Accident Analysis Using PVM," Nuclear Safety, Vol. 36, No. 1, pp. 94-108, 1995.

[3] Lee, S.Y., et al., "COBRA/RELAP5: A Merged Version of the COBRA-TF and RELAP5/MOD3 Codes," Nuclear Technology, Vol. 99, pp. 177-187, 1992.

[4] Jeong, J.J., et al., "Assessment of the COBRA/RELAP5 Code Using the LOFT L2-3 LargeBreak Loss-of-Coolant Experiment," Annals of Nuclear Engineering, Vol. 24, No. 14, pp. 1171-1182, 1997.

[5] FLOW3D Release 3.2: User Manual, AEA Industrial Technology, Harwell Laboratory, Oxfordshire, United Kingdom, 1992.

[6] Geist, A., et al., "PVM3 User's Guide and Reference" ORNL/TM-12187, Oak Ridge National Laboratory, 1994.

[7] Martin, R.P., "RELAP5/MOD3 Code Coupling Model," Nuclear Safety, Vol. 36, No. 2, pp. 290-299, 1995.

[8] Edwards, A.R and T.P. O'Brien, "Studies of Phenomena Connected with the Depressurization of Water Reactors," Journal of the British Nuclear Energy Society, Vol 9, pp. 125-135, 1970. 
TOTAL PROBLEM MODEL

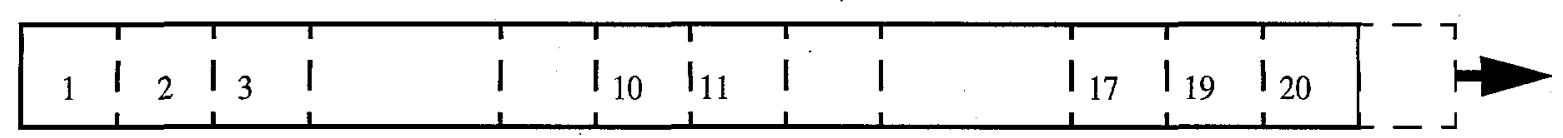

CFD (CHILD) PORTION OF MODEL

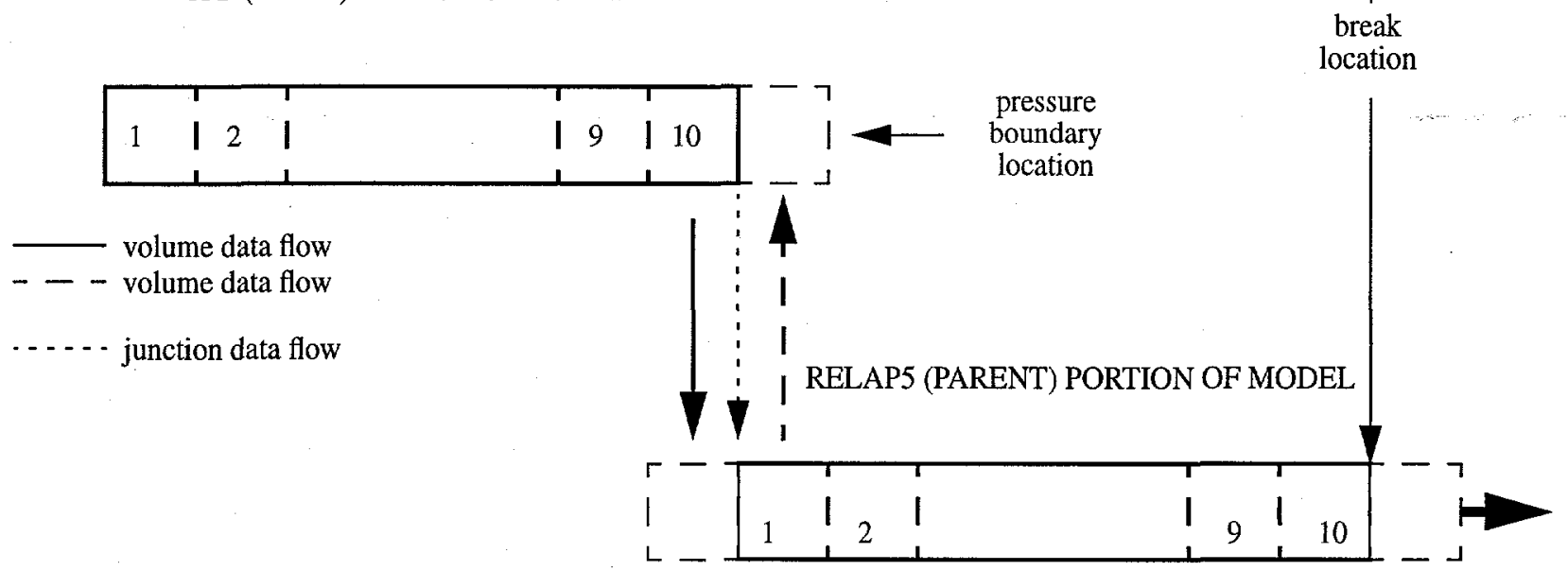

Figure 1: Nodalization for Full and Coupled Analyses

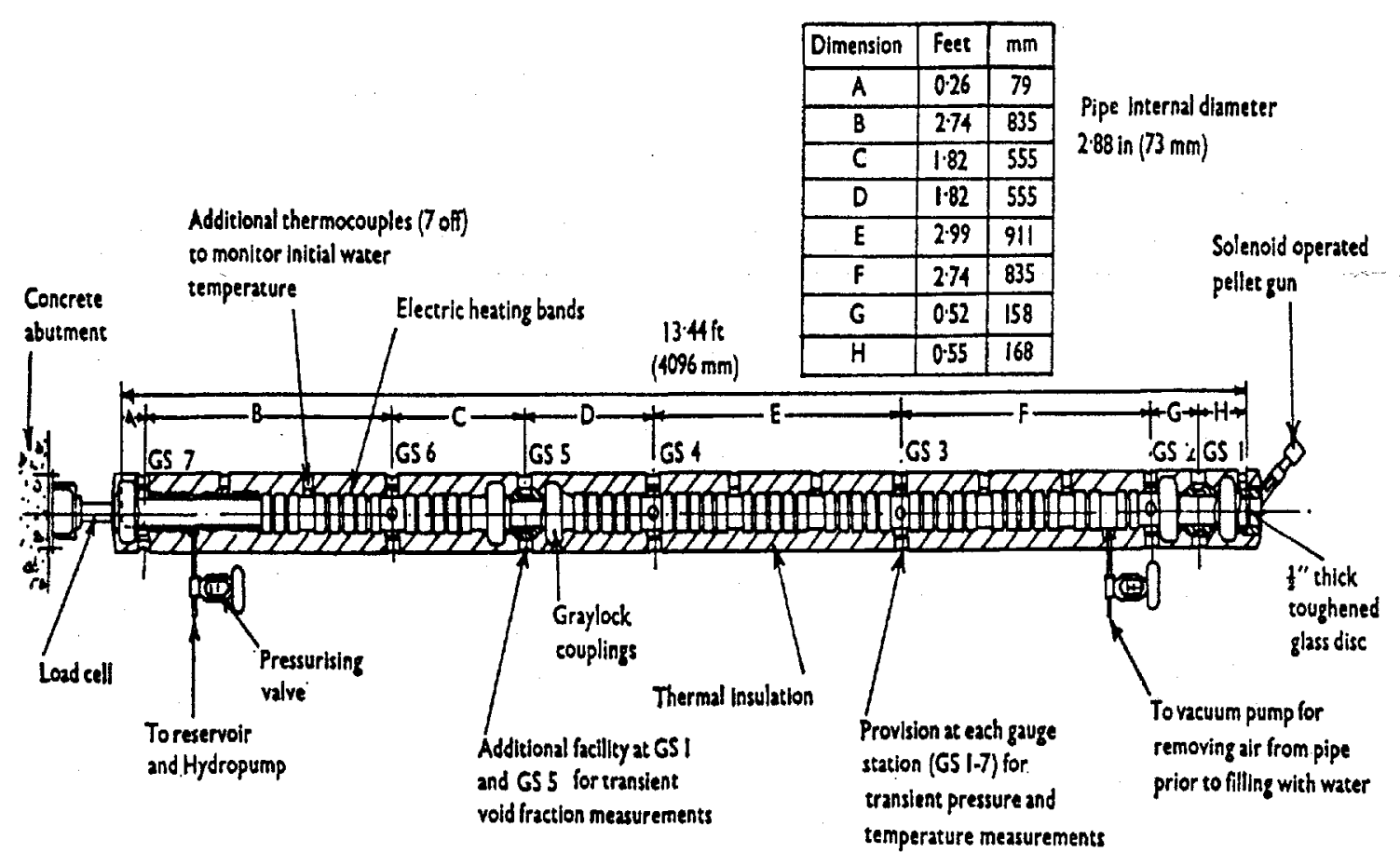

Figure 2: Edwards-O'Brien Blowdown Test (taken from [8]) 


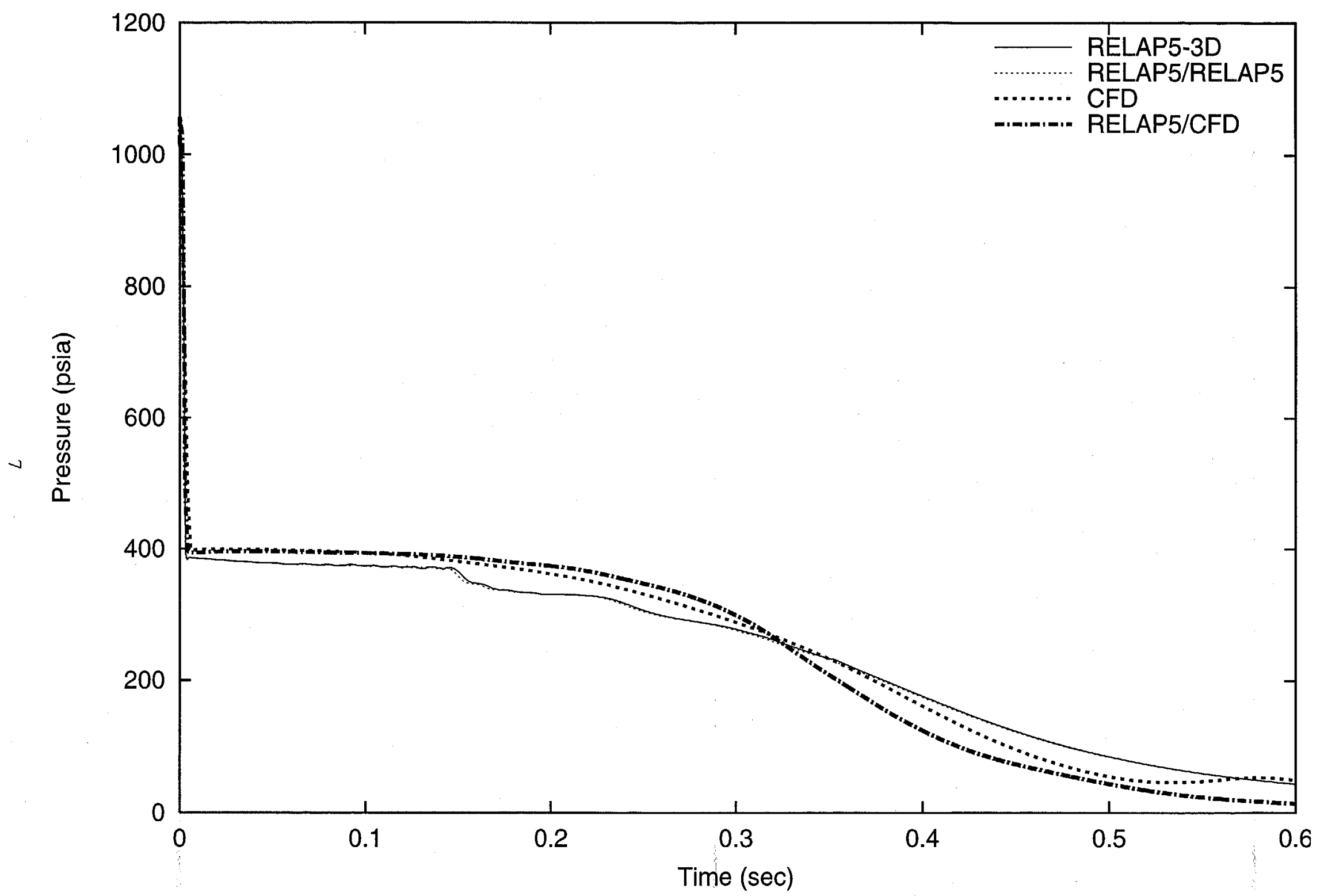

Figure 3: Pressure as a Function of Time at GS-5 


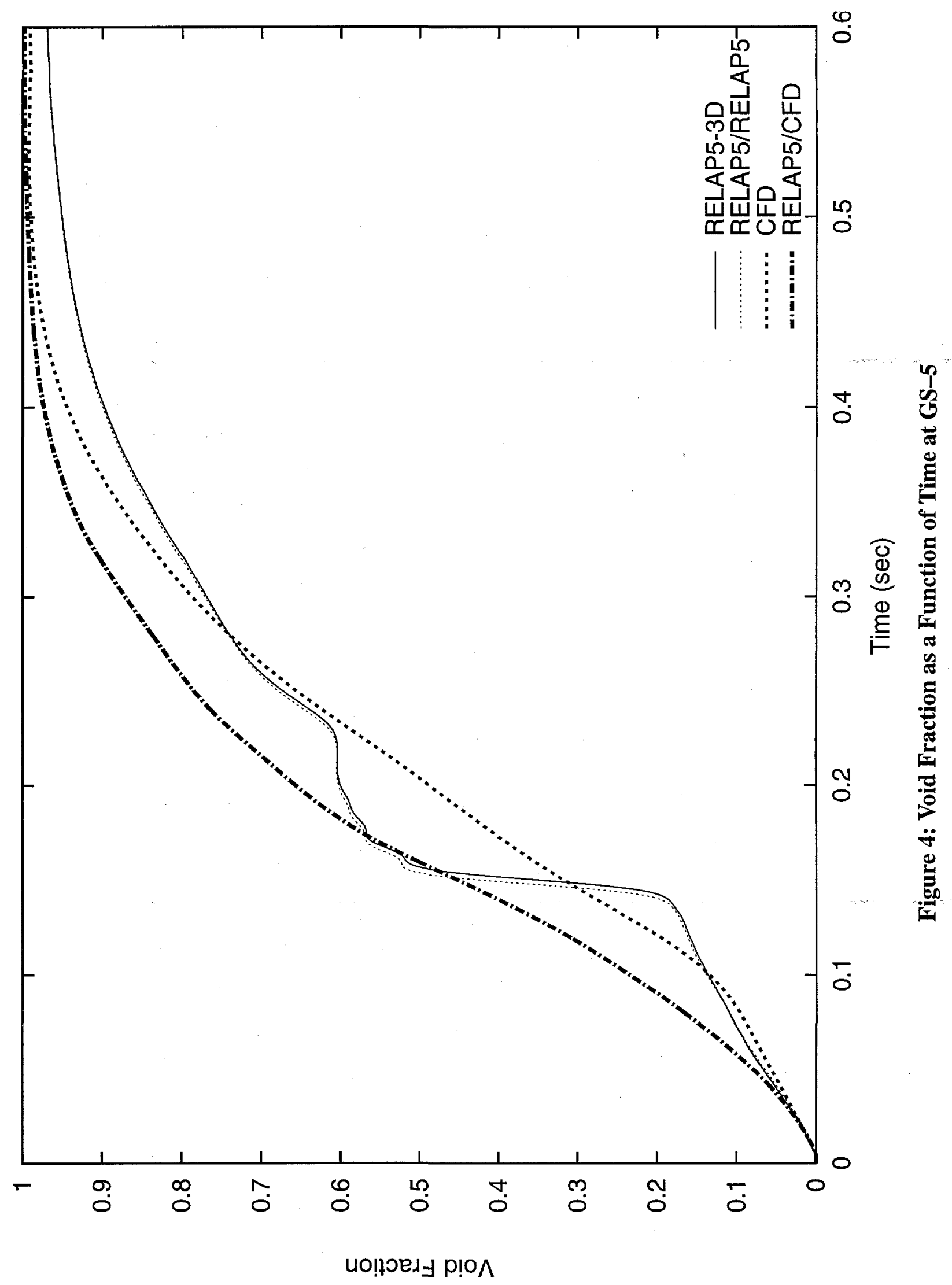




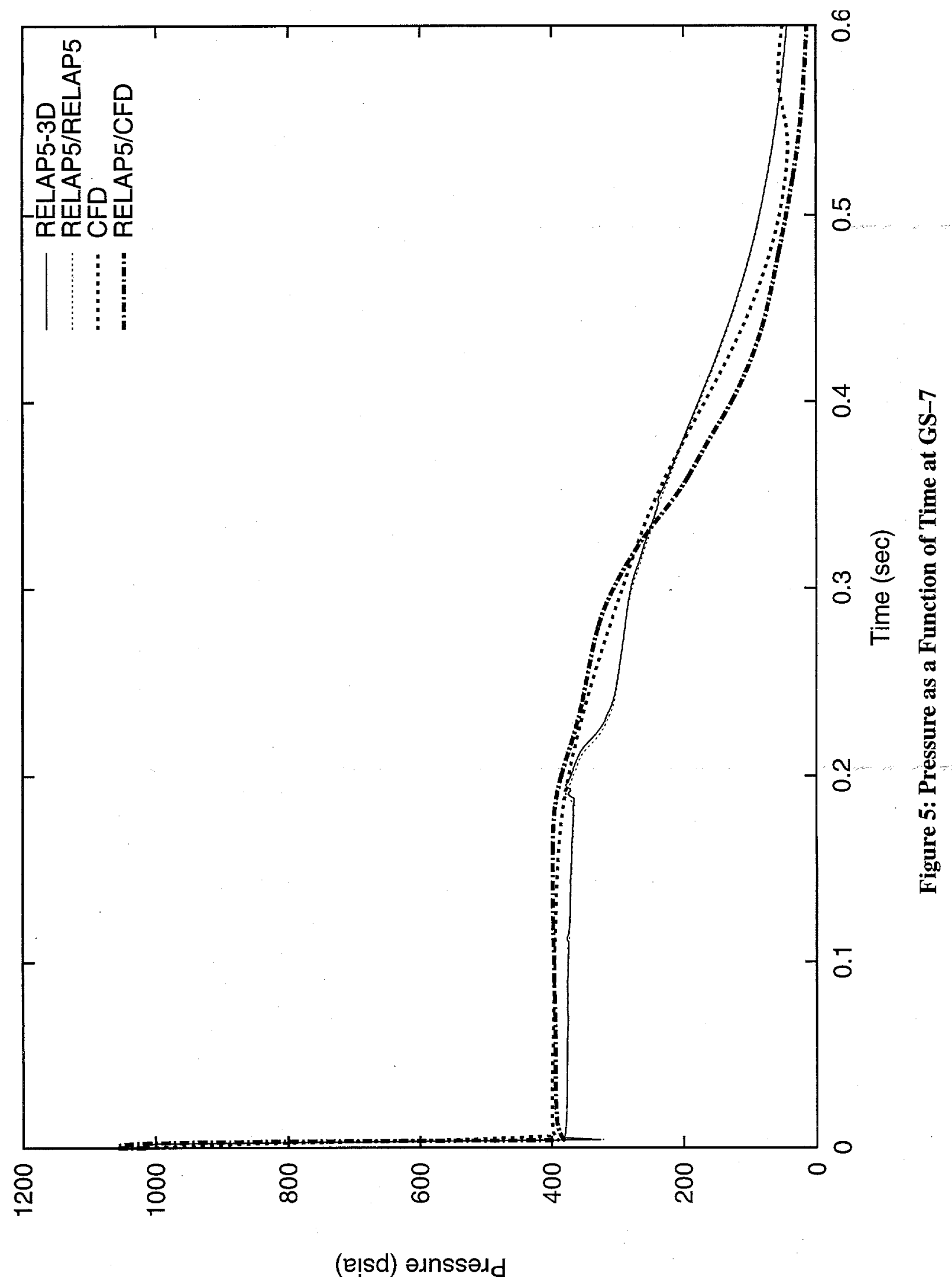




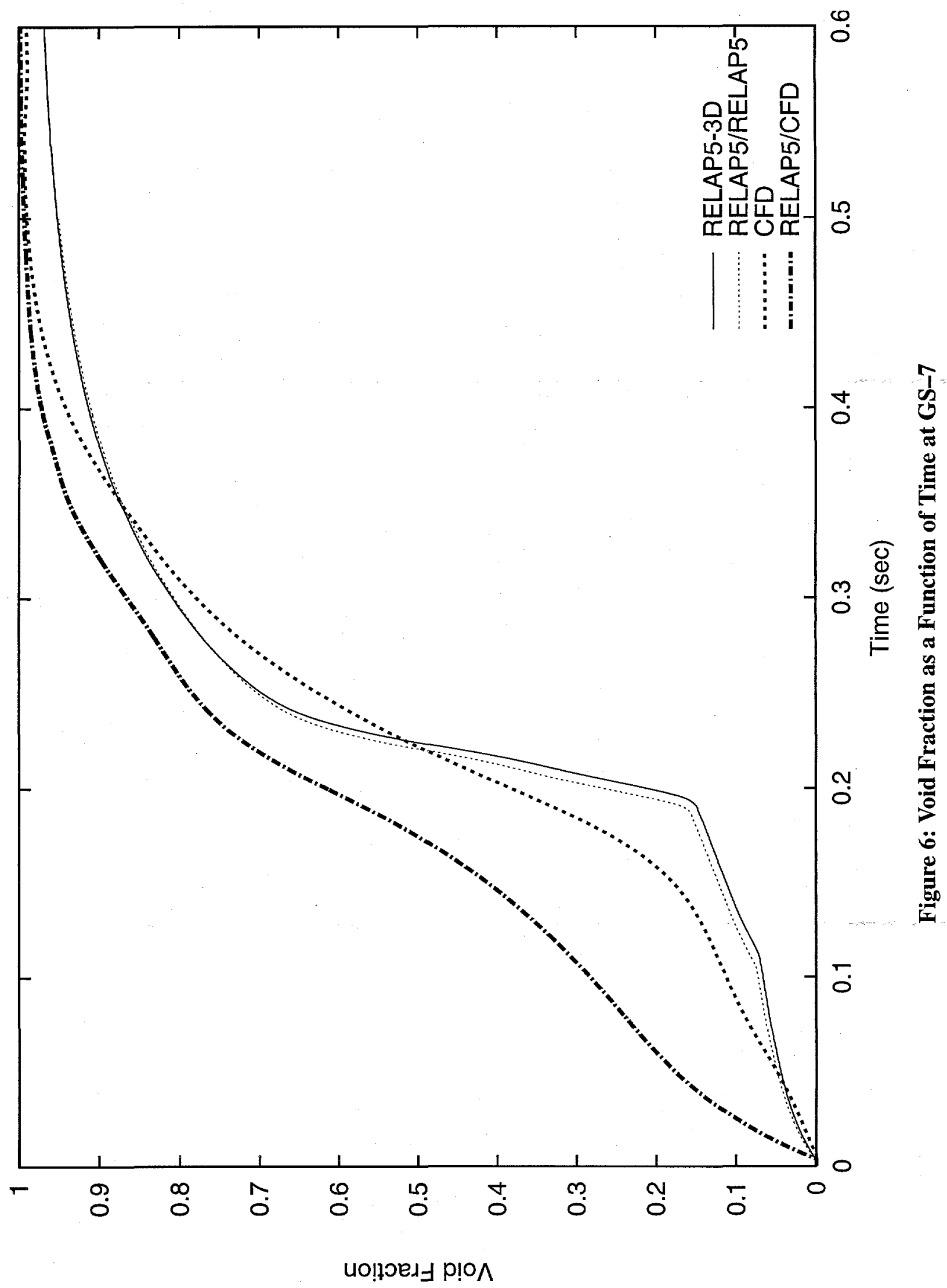




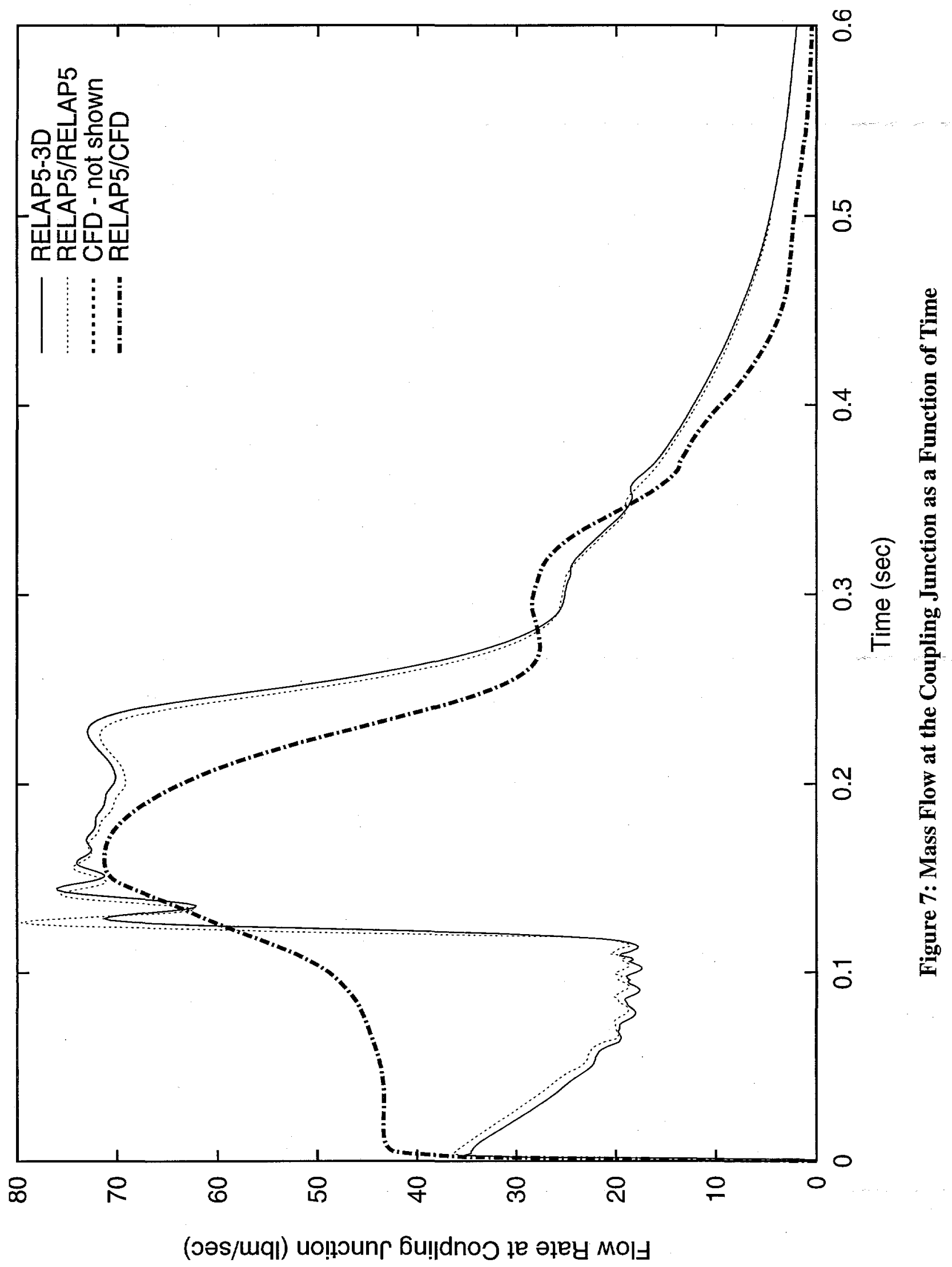




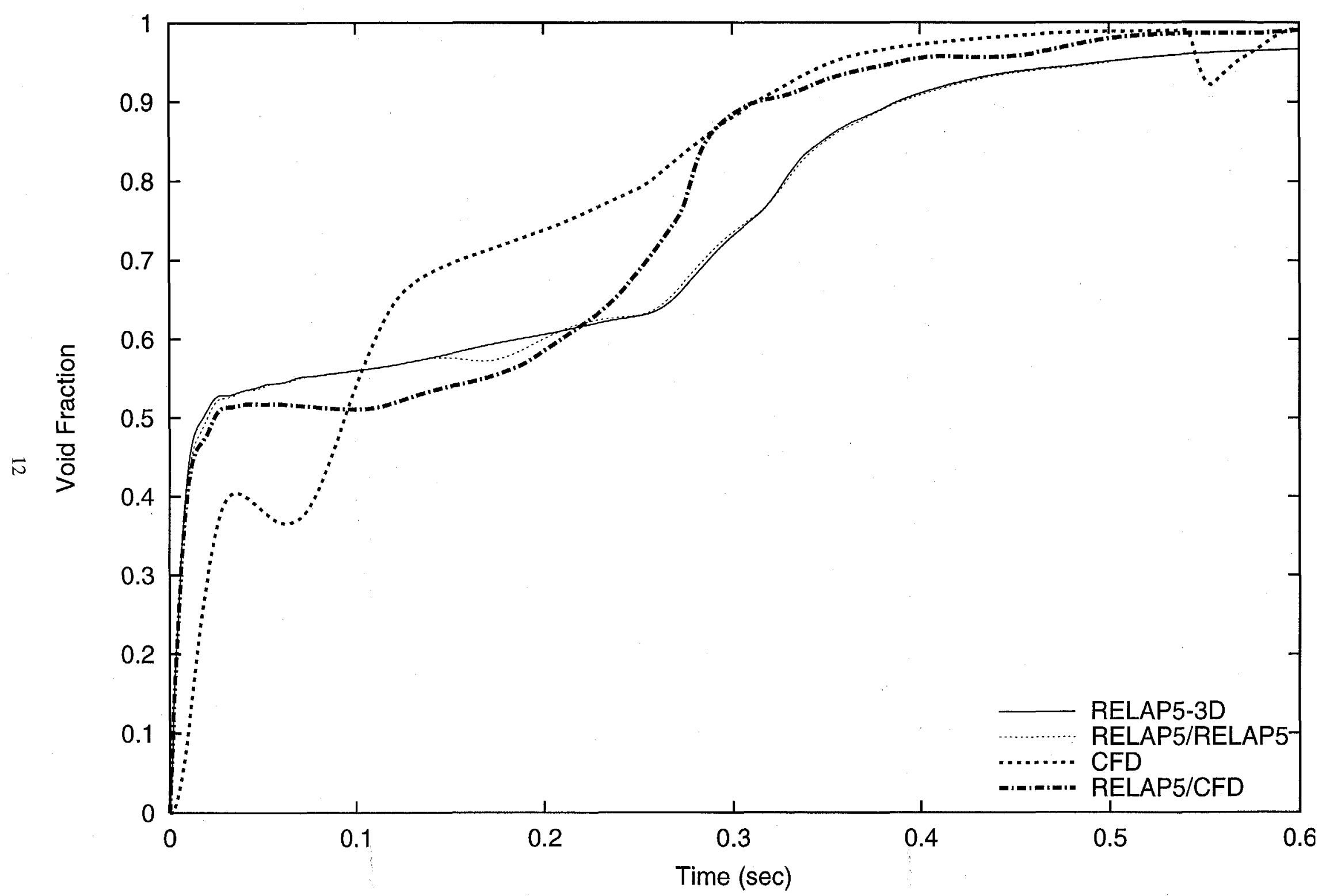

Figure 8: Void Fraction at the Exit as a Function of Time 


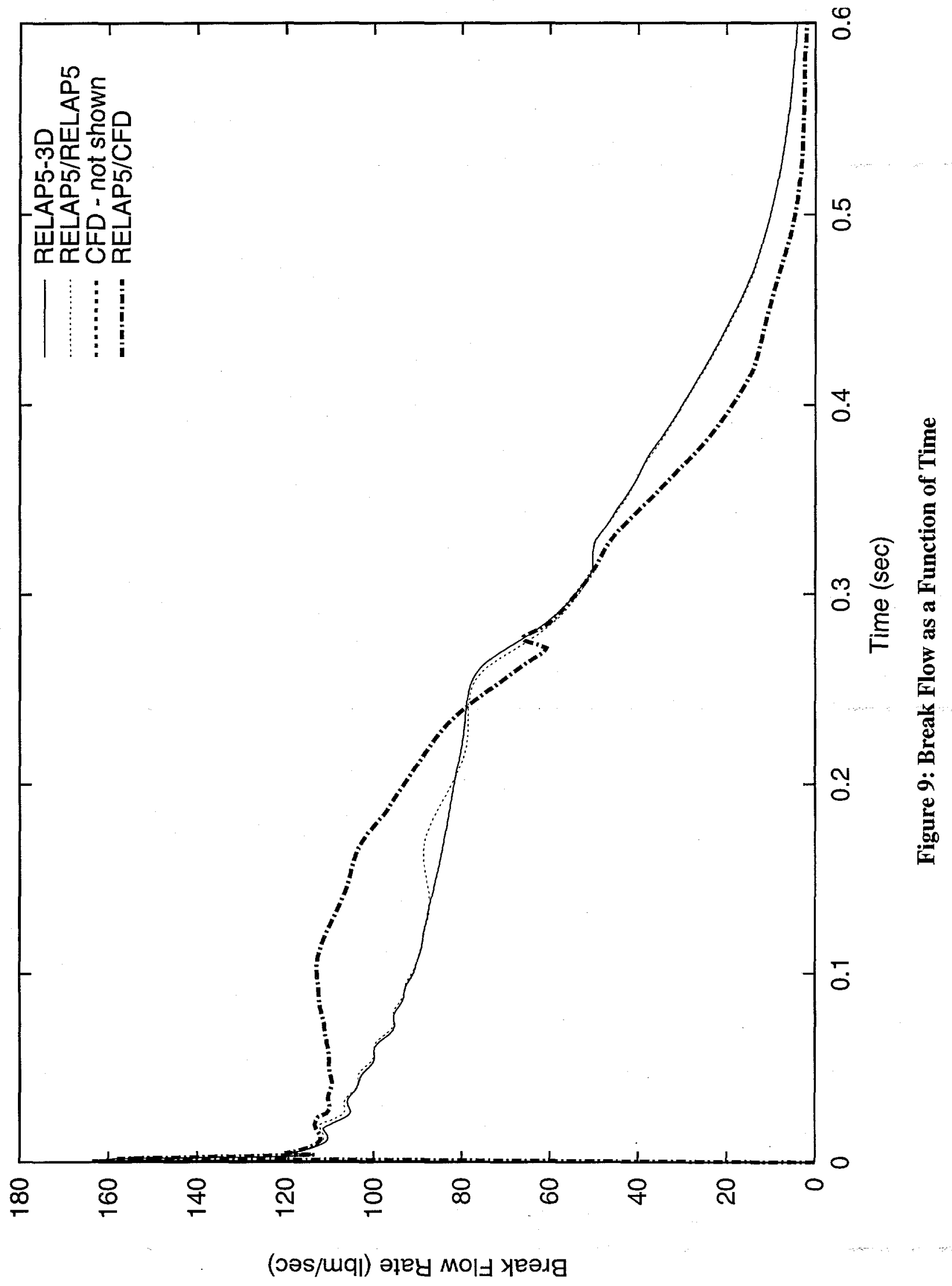

